\title{
Peat Storage Losses Investigation
}

\author{
Galina Stolbikova ${ }^{1}$, and Elena Chertkova $^{1}$ \\ ${ }^{1}$ Tver State Technical University, 22 Af. Nikitin Street, 170026, Tver, Russia
}

\begin{abstract}
The paper investigates the effect of self-heating, wetting and freezing of different milled peat types on field storage losses. It has been found that the loss of organic matter in peat due to self-heating depends on peat decay degree, type of product obtained, heating temperature (storage duration), preventive measures taken and the technological scheme of peat extraction. When such preventive measures as moving stacks, internal sealing and compaction of peat are taken, a decrease in self-heating and spontaneous combustion losses is observed. In two-stage harvesting, these losses are lower because of peat compaction in stacking operations. It has been established that there is a dependence of peat losses on its wetting and freezing, storage duration, and the total amount of precipitation accumulated over a certain period. With an increase in peat decay degree, the maximum wetting and freezing losses are several times lower than self-heating losses. These losses are $20 \%$ higher for upland peat than for lowland peat.
\end{abstract}

\section{Introduction}

On completing a peat-cutting season, milled peat is stored in storage units (stacks) in the open air from several days to 12-13 months (sometimes up to two years). During the storage, peat is exposed to precipitation, wind, deposit moisture flows, along with self-heating and spontaneous combustion in stacks. Due to precipitation, soaking a part of commercial peat goes into an off-quality state, while a part of organic peat mass is lost because of self-heating and spontaneous combustion [1-3]. The storage loss rate of peat also depends on time and duration of storage, weather conditions, nature of peat and its quality characteristics. It is important to meet rigid regulatory requirements to peat stacking and storage operations [4].

Peat storage losses are regulated by current standards being illustrated in Table 1.

Table 1. Peat storage losses.

\begin{tabular}{|c|c|c|c|}
\hline \multirow{2}{*}{ Peat product type } & \multicolumn{3}{|c|}{ Peat decay degree, \% } \\
\cline { 2 - 4 } & $\mathbf{5 2 5}$ & $\mathbf{2 6 . . . 4 0}$ & $\mathbf{7 0}$ \\
\hline Milled fuel peat & 10 & 7 & 5 \\
\hline Horticultural milled peat of high moisture content & 5 & 5 & 5 \\
\hline Litter peat & 15 & - & - \\
\hline
\end{tabular}


Planned field storage losses in enlarged peat stacks (under two-stage harvesting) are given in Table 2 .

Table 2. Peat storage losses in enlarged stacks.

\begin{tabular}{|c|c|c|c|c|}
\hline \multirow{2}{*}{ Peat product type } & \multirow{3}{*}{$\begin{array}{c}\text { Storage } \\
\text { period, month }\end{array}$} & \multicolumn{3}{|c|}{$\begin{array}{c}\text { Peat loss rates, \% } \\
\text { with peat decay degree }\end{array}$} \\
\cline { 3 - 5 } & & up to 15 & $\mathbf{1 5 \ldots 2 5}$ & $\begin{array}{c}\text { higher } \\
\text { than 25 }\end{array}$ \\
\hline Milled litter peat & 12 & 8.0 & 5.0 & - \\
\hline Pulverized fuel peat and briquetted peat & 12 & 8.0 & 5.0 & 2.0 \\
\hline Milled fertilization and compost peat & 12 & - & 4.0 & 2.0 \\
\hline
\end{tabular}

Tables 1, 2 show that standards are taken with account for qualitative characteristics of peat (peat decay degree) and its harvesting moisture depending on the type of product obtained. The influence of other factors, for example self-heating, on the loss rate is not taken into account, neither preventive measures to reduce peat heating, wetting, freezing during storage in stacks. Although in some cases, the actual losses differ significantly from those given. Therefore, there has emerged a need to study the effect of self-heating, wetting and freezing on the milled peat storage loss, as well as the utility of preventive measures.

When milled peat is stored in the field in stacks, the process of self-heating occurs because of microbiological activity and chemical reactions, which is followed by the loss of organic matter in peat. There are three methods to determine the loss of organic matter in peat:

(a) Direct weighing of peat samples having been stored in a stack in bags made of porous glass cloth. This method gives the actual loss of peat, however, it is very laborious, since to estimate losses throughout the stack, it is required to place a great number $(25 \ldots 30)$ of bags.

(b) Determination of ash content. This method is based on the post-storage ash content increase in a stack due to the loss of organic matter arising from self-heating. In fact, this method is effective for estimating the total peat losses with wind and self-heating.

(c) By semi-coking products yield. This method is also very time consuming.

Studies have shown that the heating temperature has a significant effect on the peat organic matter loss rate. The average month storage losses of lowland peat with a total storage duration of $8 \ldots 10$ months depend on the heating temperature. If it is below $70^{\circ} \mathrm{C}$, losses are $0.4 \ldots 0.6 \%$ of organic matter, at $70 \ldots 75^{\circ} \mathrm{C}$ losses increase to $0.9 \ldots 1.0 \%$, and above $75^{\circ} \mathrm{C}$ they reach $1.5 \%$ and more per month [5]. Loss of organic matter at temperatures below $70^{\circ} \mathrm{C}$ occurs primarily due to microbiological and enzymatic hyperactivity. When the temperature is above $75^{\circ} \mathrm{C}$, along with oxidative processes, thermal decomposition of peat begins. At $75^{\circ} \mathrm{C}$ and especially above it, the processes of thermal destruction increase rapidly, which are accompanied by large changes in the chemical composition of peat. These losses are significantly higher for upland peat since they reach $1 \%$ even at $60^{\circ} \mathrm{C}$ [6]. All the described processes are accompanied by temperature increase. Therefore, a method for determining the extended storage loss of organic matter by a known heating temperature has become relevant.

\section{Method used}

The object of the study is milled lowland and upland peat sorted into three decay degree groups: less than $15 \%$, from 15 to $25 \%$ and more than $25 \%$. The type of products obtained is the fuel with a relative humidity of $40 \%$ and the peat with a high moisture content of $55 \%$ for farming and other purposes. Preventive measures are also taken into account: (a) moving 
stacks in the course of extraction, internal sealing, compaction; (b) layer-by-layer compaction and end-of-season sealing.

Self-heating losses of milled peat occur during the entire storage period and increase proportionally to the shelf life and heating temperature [7]. To the first approximation, the minimum self-heating losses can be calculated as follows.

Quantity of heat $(Q)$ required raising the temperature of peat from temperature $t_{1}$ to $t_{2}$ is determined by formula:

$$
Q=C_{\mathrm{q}} \cdot m\left(t_{2}-t_{1}\right)
$$

where $C_{\mathrm{q}}$ is peat specific heat capacity, $\mathrm{kJ} / \mathrm{kgK} ; m$ is peat mass equal to $1 \mathrm{~kg} ; t_{1}$ and $t_{2}$ are initial and final storage temperatures of peat, $\mathrm{K}$.

Specific heat capacity is determined by formula:

$$
C_{\mathrm{q}}=1,97+4,19 \cdot W
$$

where $W$ is moisture content of peat, $\mathrm{kg} / \mathrm{kg}$.

Heat losses, $\%$ are as follows:

$$
L_{\mathrm{h}}=\frac{Q}{Q_{\mathrm{h}}} 100
$$

where $Q_{\mathrm{h}}$ is heating capacity of peat, $\mathrm{kJ} / \mathrm{kg}$.

It should be noted that the abovementioned calculation of heat losses does not take into account the heat exchange of peat in a stack with ambient air. Therefore, the actual value of self-heating losses of peat during the storage period is much higher.

Loss rate is calculated for peats with similar characteristics in terms of the type and the peat decay degree. The average rate of losses is calculated for a specific peat deposit development (site) as a dynamic average for individual areas (fields).

Overall losses over the storage period (\%) are determined as the total of peat organic matter losses and wetting and freezing ones.

$$
L_{\mathrm{o}}=L_{\mathrm{om}} \cdot \tau_{\mathrm{xp}}+L_{\mathrm{w} . \mathrm{f}}
$$

where $L_{\mathrm{om}}$ is the loss of peat organic matter due to self-heating for a month storage period, $\% ; \tau_{\mathrm{xp}}$ is storage period duration, months; $L_{\mathrm{w} . \mathrm{f}}$ are wetting and freezing losses, $\%$.

\section{Results and Discussions}

Month storage losses of milled peat due to self-heating under various preventive measures conditions are given in Figure 1. The graphs show that with an increase in peat decay degree the self-heating losses tend to decrease both for fuel peat (Fig. 1a) and for high moisture content peat (Fig. 1b). Moreover, for fuel peat outside the preventive measures conditions, these losses are about $30 \ldots 50 \%$ higher. (Fig. 1, curve 1). When such preventive measures as moving stacks, internal sealing and compaction of peat are taken, the fuel peat losses decrease by $20 \%$ and those for high moisture content peat do by $15 \%$ (Fig. 1, curve 3 ). With a layerby-layer compaction during the harvesting and stacking and the end-of-season sealing, even a greater decrease in losses is observed, namely by 30 to $70 \%$ for fuel peat and by 30 to $40 \%$ for high moisture content peat. (Fig. 1, curve 4). In case of two-stage harvesting (Fig. 1, curve 5 ), the decrease in losses is from 30 to $45 \%$ for both fuel peat and high moisture content peat. Such a significant decrease in peat losses occurs due to peat compaction during stacking 
operations. Peat is moved from the base to the top of a stack when a bulldozer-stacker makes the ramped approach to the stack.

a

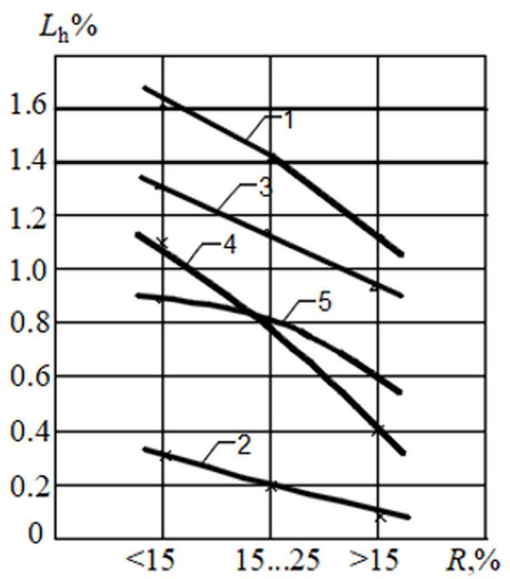

$b$

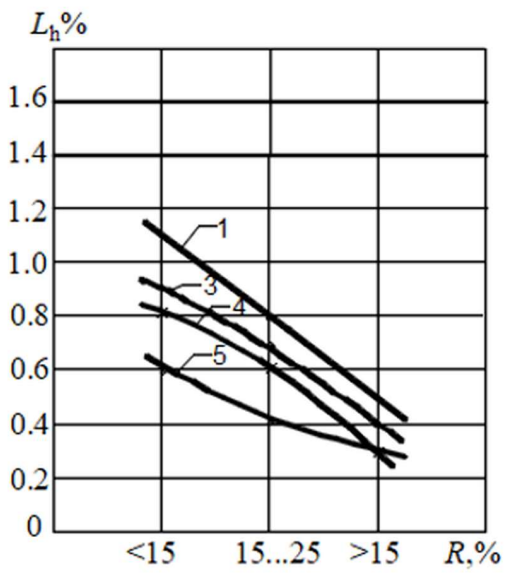

Fig. 1. Month storage losses of milled peat due to self-heating (\%) depending on peat decay degree R: $a$ - for fuel peat harvesting, $\omega_{\mathrm{y}}=40 \% ; b$ - for high moisture content peat harvesting, $\omega_{\mathrm{y}}=55 \%$. Under preventive measures conditions: 1 - without them; 2 - sealing with polyethylene film; 3 moving, internal sealing, compaction; 4 - layer-by-layer compaction, end-of-season sealing; 5 - twostage harvesting.

Milled peat losses due to wetting and freezing $\left(L_{\mathrm{w} . f}, \%\right)$ can be determined depending on the thickness of the wet and frozen layers $\left(h_{\mathrm{w.f}}\right)$ and the stack size (its height $\left.H_{\mathrm{ST}}\right)$. Wetting and freezing losses depending on peat decay degree $R$ and the amount of precipitation $\Sigma h_{\mathrm{P}}$ are shown in Fig. 2.

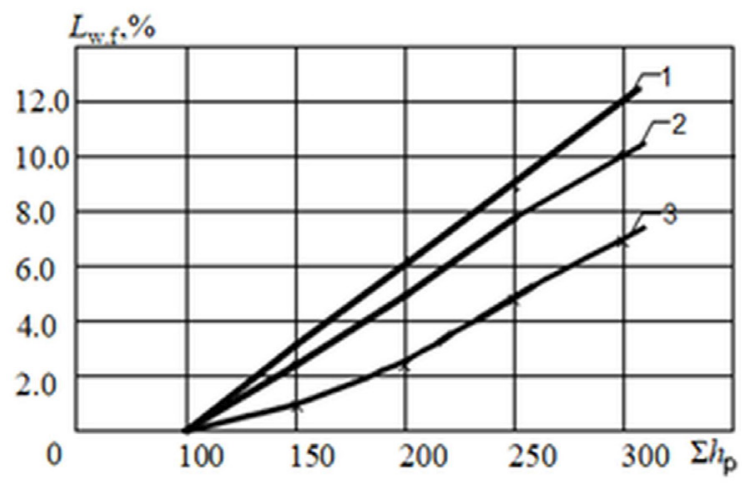

Fig. 2. Milled peat losses due to wetting and freezing at different precipitation rates during a storage period (\%) and with various peat decay degree R: 1 - up to $15 \% ; 2-15 \ldots 25 \% ; 3$ - more than $25 \%$.

When it is necessary to determine the wetting and freezing losses of peat, the total amount of precipitation accumulated for the period from September to consumer delivery is taken into account. As it is seen from the analysis of functions plotted, the wetting and freezing losses decline dramatically with the increase in peat decay degree. Specifically, if peat decay degree increases from 15 to $25 \%$, the decline is about $20 \%$ (from 3 to $2.5 \%$ ), if peat decay degree increases up to $25 \%$ (from 3 to $1 \%$ ) the decline is three-fold, with total precipitation 
rate over a storage period being $150 \mathrm{~kg} / \mathrm{m}^{2}$. If the total precipitation increases, wetting and freezing losses increase several times. With the increase in precipitation amount by a factor of 2 from 150 to $300 \mathrm{~kg} / \mathrm{m}^{2}$, wetting and freezing losses of peat with a decay degree $<15 \%$ increase four times and makes $12 \%$, while for peat with peat decay degree $>25 \%$, these losses are as little as $7 \%$. Such a decrease in peat losses occurs because in low decay degree peat the more undecomposed particles of peat-forming plants with high water-absorbing ability are retained.

When peat is sealed with a polyethylene film or a wet peat layer of $40 \mathrm{~cm}$ thick, peat wetting losses are equal to zero. When peat is extracted by two-stage harvesting method, precipitation and low temperature losses are cut in half.

Based on the study of technological schemes of milled peat storage in stacks in open air and taking into account the data of peat production associations and enterprises engaged in extraction, storage and transportation of finished peat products, the average values of peat natural loss during its storage have been determined. The values of natural loss of milled fuel peat $\left(\omega_{\mathrm{y}}=40 \%\right)$, milled peat of high moisture content for horticultural purposes and production of consumer goods $\left(\omega_{\mathrm{y}}=55 \%\right)$ made of lowland and upland peat are shown in Figure 3. The analysis shows that all the losses of upland peat (Fig. $3 b$ ) are much higher than lowland peat losses (Fig. 3a). This is especially typical of peat that is stored outside the preventive measures conditions (Fig. 3, curve 1). When preventive measures are taken (Fig. 3 , curves 2 and 3), self-heating losses of organic matter are significantly reduced against the increase in peat decay degree. This reduction is higher when a layer-by-layer compaction and an end-of-season sealing of peat are applied (curve 3). Self-heating losses in two-stage harvesting are far less (curve 4). The maximum wetting and freezing losses are several times lower than self-heating ones (Fig. 3, curve 5). With the increase in peat decay degree, they decline from 6.5 to $2.5 \%$.

$a$

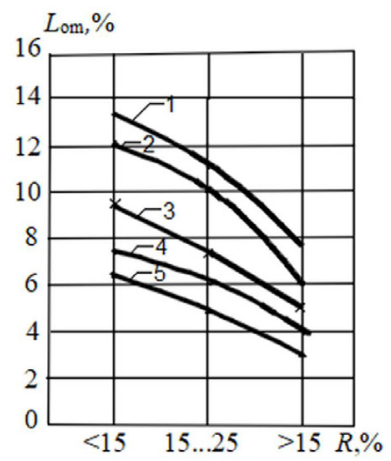

\section{$b$}

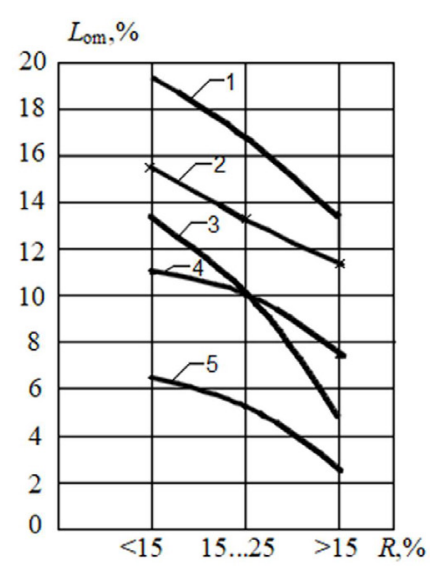

Fig. 3. The values of storage losses: $a$ - for lowland peat; $b$ - for upland peat, depending on peat decay degree $R$ under self-heating and preventive measures conditions 1 - without preventive measures conditions; 2 - stack moving, internal sealing, compaction; 3 - layer-by-layer compaction and end-of-season sealing; 4 - two-stage harvesting; 5 - maximum losses due to wetting and freezing.

When determining the planned amount of loss and designing peat deposits development, the shelf life of milled peat is taken as 12 months. Milled peat losses may also occur via the spillage in loading and the blowing-out by airflow in the course of transportation to a consumer. In order to reduce these losses, it is advisable to compact peat and apply protective 
coatings to the open surface of peat in a vehicle. The transportation losses of peat should not exceed $0.2 \%$ of the net weight of cargo.

\section{Conclusions}

Thus, the studies carried out indicate that the self-heating losses of peat organic matter depend on peat decay degree, heating temperature, storage duration and preventive measures taken, as well as peat type and the technological scheme of extraction. With an increase in peat decay degree, the loss of peat decreases. These losses are higher for upland peat than for lowland peat by more than $20 \%$. When such preventive measures as layer-by-layer compaction, stack moving, internal sealing and end-of-season sealing are taken, the losses decrease by $15 \ldots 20 \%$. In the scheme of peat extraction with two-stage harvesting, selfheating losses are reduced 1.5...2.0 times. Wetting and freezing losses of peat are reduced from 6.5 to $2.5 \%$; they depend on storage duration and the total amount of precipitation accumulated over a certain period.

\section{References}

1. Panov V.V., Misnikov O.S., Gornyi Zhurnal, 2015, 7, 108-112 (2015)

2. Zyuzin B.F., Misnikov O.S., Panov V.V., Kopenkina L.V. Gornyi Zhurnal, 2013, 5, 7376 (2013)

3. O. Misnikov, Mires and Peat, 18:22, 1-15 (2016)

4. A. Afanas'ev, A. Boltushkin, Colloid Journal of the Russian Academy of Sciences: Kolloidnyi Zhurnal, 58, 2, 139-144 (1996)

5. E. Kremcheev, D. Nagornov, Life Science Journal, 11, 11, 453-456 (2014)

6. V. Belyakov, A. Kuporova, E3S Web of Conferences. 3rd International Innovative Mining Symposium, IIMS, 41, 01047, (2018)

7. V. Lebedev, O. Puhova, E3S Web of Conf., 15, 01018 (2017) 